www.nature.com/jhg

\title{
Huntington disease-like 2 (HDL2) in Venezuela: frequency and ethnic origin
}

\author{
Irene Paradisi, Vassiliki Ikonomu and Sergio Arias
}

Huntington disease (HD) phenotypes without a HTT mutation are known as HD-like (HDL) syndromes and are caused by mutations in other loci. HDL2, almost indistinguishable from HD, is due to expansions in the Junctophilin 3 locus (JPH3) with a worldwide Sub-Saharan ethnic origin. Sixteen independent patients with involuntary movements, psychiatric disturbances and ataxia not having a HTT mutation were searched for loci PRNP (prion protein, HDL1), JPH3 (HDL2), ATN1 (dentatorubralpallidoluysian atrophy), ATX2 (spinocerebellar ataxia 2) ATXN3 (spinocerebellar ataxia 3), and TBP (spinocerebellar ataxia 17 = HDL4). Markers Duffy, Kell, Diego, D9S1120, plus six JPH3 intragenic single-nucleotide polymorphisms were tested to ascertain ethnic origin. Four unrelated choreic patients had an expanded allele at JPH3. Three of them carried the African marker Duffy null. All four families carried with the mutation the same haplotype most frequent in African populations; Amerindian alleles D9D1120*9 and Diego A; or Kell allele K were absent. HDL2 in Venezuela had a low, but higher relative frequency $(2.6 \%)$ than that in other Caucasoid populations. It should be searched first in choreic patients not having HTT mutations. The most likely remote ethnic origin for all detected families was African.

Journal of Human Genetics (2013) 58, 3-6; doi:10.1038/jhg.2012.111; published online 13 September 2012

Keywords: abnormal movements; ethnic origin; genetic epidemiology; HDL2; Huntington disease-like; neurodegenerative disorders

\section{INTRODUCTION}

Huntington disease-like (HDL) syndromes are a group of inherited diseases in which the classic triad of involuntary movements (chorea), cognitive decline and psychiatric disturbances are present, without expansion mutations at the HD locus (HTT). To date, four subtypes of HDL are recognized, based on their locus mutation. HDL1 is caused by an octapeptide repeat expansion in the PRNP gene at 20p12. HDL2 is caused by a CAG/CTG trinucleotide repeat expansion in the Junctophilin 3 locus (JPH3) gene on 16q24.3. ${ }^{2}$ HDL3 has only been reported in a Saudi Arabian family with an autosomal recessive pattern; the locus was mapped to $4 \mathrm{p} 15.33^{3}$ and HDL4 is a spinocerebellar ataxia (SCA17) caused by mutations at the TATA box-binding protein gene TBP $(6 \mathrm{q} 27) .{ }^{4}$ Some other mutated genes can cause clinical manifestations overlapping the HD phenotype; the main ones so far are the dominant spinocerebellar ataxias SCA1 (6p23), SCA2 (12q24), SCA3 (14q32.1) and DRPLA (dentatorubral-pallidoluysian atrophy, 12p13.31). ${ }^{5}$ Mutations in those loci account only for a small proportion of patients with a HD phenotype. Disease subtypes have different population frequencies, and HDL4 (SCA17) has a frequency around 3\% in several Caucasoid populations, ${ }^{4}$ but it has also been reported in Japanese and Mexican patients, ${ }^{6,7}$ although not in Africans. On the contrary, HDL2 has only been reported in Africans or Afro-descendant patients, being absent in Japanese. 8 ,9
Herein we report four independent Venezuelan families with a HDL phenotype and mutations at JPH3, with a probable Sub-Saharan remote ancestral origin for the mutated allele.

\section{MATERIALS AND METHODS}

Sample

A total of 16 out of 153 genetically independent index cases who presented with involuntary movements, psychiatric symptoms and ataxia were studied. They were referred to the Human Genetics Laboratory at the Venezuelan Institute for Scientific Research (IVIC) for both a molecular diagnostic search of HD and for genetic counseling; those which had not a CAG trinucleotide expansion at the HTT locus were further ascertained for other possible mutated genes: PRNP (HDL1), JPH3 (HDL2), TBP (HDL4 ESCA17), ATXN2 (SCA2), ATXN3 (SCA3) and ATN1 (DRPLA).

Precise places of birth of remote ancestors (grandparents and great-grandparents) were established in each family; a family history for phenotype and age of onset of symptoms was recorded. A 5-ml blood sample was withdrawn, EDTA anticoagulated, and DNA was extracted by a saline method as usual. ${ }^{10}$

Written voluntary informed consent was obtained from all family members, according to the institutional ethical guidelines.

DNA analyses. PRNP gene: primers PRNPf 5'-GGATGCTGGTTCTCTTTGT- ${ }^{\prime}$ and PRNPr 5'-TGTTGGTTTTTGGCTTACTC- $3^{\prime}$, including the PRNP octapeptide repeats, were designed with Primer3 program (available at http:// 
frodo.wi.mit.edu/). SCA17: primers TBP-F and TBP-R previously reported ${ }^{11}$ were used to assess trinucleotide allele size. SCA2: primers UH13 and UH10 and PCR conditions previously reported ${ }^{12}$ were used to amplify ATXN2 alleles. SCA3: primers MJD52 and MJD25 ${ }^{13}$ were used with a long PCR program. DRPLA: CTG-B37 primer set was used to amplify the CAG-repeat regions. ${ }^{14}$ JPH3 gene: primers HDL2f 5'-CTCCATGCGTGTCAGGTG-3' and HDL2r $5^{\prime}$ TCAGTGAGAGCCCAGGAATC- $3^{\prime}$ were designed with Primer3 program to amplify the region containing the CAG/GTC-repeat tract. Actual number of repeats was established in PCR products by sequencing at Macrogen Service, Seoul, Korea.

JPH3 polymorphisms: six intragenic single-nucleotide polymorphisms (SNPs) were used to construct haplotypes. Four of the six SNPs located at exon 2, one at intron 3 and the other at intron 4. Exon 2 partial amplicon included polymorphisms rs918368 (917C > T, S221S), rs3751725 (938G > A, S228S), rs34442559 (992C > T, S246S) and rs9934222 (1022G >A, T256T); these four SNPs are located in a consecutive stretch of $106 \mathrm{bp}$. Intron 3 polymorphic site (rs1366520, G/C) is approximately $40 \mathrm{~kb}$ far apart from exon 2. Intron 4 polymorphism, rs $8053904(\mathrm{G} / \mathrm{C})$, is located approximately $20 \mathrm{~kb}$ downstream from intron 3 polymorphism. At the JPH3 locus, there is no allelic disequilibrium between chosen SNPs (HapMap phase 3; http://hapmap.ncbi. nlm.nih.gov/index.html). All patients' genotypes at the six polymorphic sites were confirmed by sequencing, using Macrogen Service. Designed primers to amplify these SNPs are available under request.

Ethnic markers: in order to ascertain probable ethnic origins in the HDL2 families, four different ethnic polymorphisms were searched: the African Duffy null allele $\left(\mathrm{FY}^{\star} 0\right.$, at 1q21), the European (Caucasoid) Kell blood group allele $\mathrm{K}$ $\left(K E L^{\star} K\right.$, at $\left.7 \mathrm{q} 33\right)$, the Amerindian/Asian Diego A blood group (SLC4A1 ${ }^{\star} A$ at 17q21) and the microsatellite D9S1120 with its allele 9, which is unique to Amerindians, were amplified using published primers ${ }^{15}$ (http://alfred. med.yale.edu). Allele 9 size ( $275 \mathrm{bp}$ ) was confirmed by sequencing. Designed primers for the blood polymorphisms are available under request.

\section{RESULTS}

Of the sixteen index cases, which did not have a mutation at the HTT locus, four had instead an expanded allele at the JPH3 locus; one had an expanded allele at ATXN3 (SCA3), another one had a mutation at ATXN2 (SCA2) and two other families had DRPLA. None had either HDL1, HDL3 or HDL4.

Mutation screening for HDL2 was further performed in family members of index cases, and two additional carriers were detected. In all the index cases, one parent was also phenotypically affected, and dominant segregation was clear in the four families. Table 1 shows expanded allele sizes, age of onset in the studied patients and main clinical manifestations at disease onset.
Normal allele size range, estimated from control individuals (from 54 chromosomes), was 13-22 CAG/CTG repeats, allele 14 being the most frequent (Table 2), as in other populations. ${ }^{8,16}$

Remote ancestors in the four HDL2 families were born in Venezuela, and three of the families came from geographic areas in which African slaves were introduced during sixteenth to seventeenth centuries, along the northeastern and northwestern coasts of the country (families 1, 3 and 4, Table 3 ). The fourth-family ancestors (family 2, Table 3), however, came from a geographic area in which African slaves made a nonimportant ethnic component. The Amerindians, as in most geographic areas still at the end of the colonial period, were the main group as reported in the qualified ecclesiastical census of bishop Martí in his exhaustive pastoral visit of Venezuela between 1771 and $1784 .{ }^{17}$ Those documents are considered today as '...the best and most complete pool of data on that (historical) period which has reached us. ${ }^{18}$

In order to ascertain a plausible African origin for the HDL2 families, detection of the specific Duffy null marker allele was accomplished. It was present in the three families (no. 1, 3 and 4) with reliable remote African ancestors, according to historical records, but it was not so in the fourth family (no. 2, Table 3 ). In the latter, neither the Amerindian marker D9S1120*9 nor the Diego allele $S L C 4 A 1^{\star} \mathrm{A}\left(\mathrm{DI}^{\star} \mathrm{A}\right)$ was carried by the index case; nevertheless, none of these marker loci locate on chromosome 16, where the JPH3 locus is present; Diego allele A and Kell allele $\mathrm{K}$ were absent in the four families. Thus, although Amerindian and Caucasoid descent might be the main ethnic background in them, a positive Sub-Saharan contribution was confirmed in three of them according to these markers, whose general population frequencies were D9S1120*9= 0.145 ( $n=200$ chromosomes), $\mathrm{FY}^{\star} 0=0.15$ ( $n=54$ chromosomes), Kell ${ }^{\star} \mathrm{K}=0.019$ ( $n=1180$ chromosomes $)$ and $\mathrm{DI}^{\star} \mathrm{A}=0.00 \quad(n=58$ chromosomes).

A remote common ethnic origin for the mutation in the country was ascertained through haplotype analysis using six intragenic SNPs. Haplotype in phase with the JPH3 mutation was identical in the four families (Table 3), whereas in the control population sample $(n=15$ individuals), there were at least three other different haplotypes: C;A;C;G;G;C (16.6\%); T;G;C;G;G;C (10.0\%); and T;G;C;G;C;G (6.7\%). Haplotype C;G;C;G;G;C in phase with Venezuelan $J P H 3$ mutations had a frequency of $10.0 \%$ in the control sample. Reported population allele frequencies of the polymorphisms used to construct the haplotypes show high heterozygosity in different ethnic groups,

Table 1 Age of onset and clinical features in Venezuelan index cases of each family with HDL2

\begin{tabular}{|c|c|c|c|c|}
\hline Family & $\begin{array}{l}\text { HDL2 genotype (no. of } \\
\text { repeats) in index case }\end{array}$ & $\begin{array}{l}\text { Age at onset } \\
\text { and sex }\end{array}$ & Clinical manifestations at onset & Imaging findings \\
\hline 1 & $16 / 39$ & $55 \mathrm{~F}$ & $\begin{array}{l}\text { Personality changes (aggressiveness) and insomnia. } \\
\text { Involuntary movements } 1 \text { year after. }\end{array}$ & Not available. \\
\hline 2 & $15 / 45$ & $46 \mathrm{~F}$ & $\begin{array}{l}\text { Insomnia and depression. Involuntary movements } \\
\text { time after. }\end{array}$ & Not available. \\
\hline 3 & $14 / 47$ & $38 \mathrm{M}$ & Involuntary movements and depression. & $\begin{array}{l}\text { Cortical and caudate atrophy at age } 40 . \\
\text { Increased volume of the ventricular system. }\end{array}$ \\
\hline 4 & $16 / 41$ & $\ll 66^{\mathrm{a}} \mathrm{F}$ & $\begin{array}{l}\text { Insomnia and psychiatric manifestations (aggres- } \\
\text { siveness). Involuntary movements time after. }\end{array}$ & Not available. \\
\hline
\end{tabular}

Abbreviations: HDL, Huntington disease-like; F, female; M, male.

Abrecise data were unavailable; two asymptomatic daughters ( 32 and 40 years) carry 42 repeats each.
aprestiations: 
including the Venezuelan population (Table 4); thus, the common haplotype found in Venezuelan HDL2 families might suggest a very remote common origin for the mutation (not necessarily a founder effect in the country), most probably from African Sub-Saharan populations. Three of the studied SNPs (rs3751725, rs1366520 and rs8053904) clearly differentiate African populations from Caucasoid and Asian ones. Furthermore, the four Venezuelan HDL2 families carried the most frequent African alleles in the haplotype in phase with the mutation, and besides, three of the index cases had the specific African marker Duffy null.

\section{DISCUSSION}

The proportion of patients not having an expanded allele at the HTT locus, with the clinical classic phenotype of $\mathrm{HD}$, is around $8 \%$ worldwide..$^{5}$ In the studied sample, $10.5 \%(16 / 153)$ of the index cases had two normal-sized alleles in that gene, discarding thus a HD diagnosis. Mutation screening in the known HDL syndromes and related genes (PRNP (HDL1), JPH3 (HDL2), TBP (HDL4), SCA3, DRPLA and SCA2) was informative in 8 out of 16 patients $(50.0 \%)$, which was considerably high, compared with reported studies in which mutation detection in HDL patients is around $3 \% .^{5}$ Of the latter, expansions at ATXN3 and ATXN2 loci were found in one family each, respectively, and ATN1 in two families; besides, four families had expanded alleles at the JPH3 gene, representing $25.0 \%$ (4/16) of the HTT negative cases; therefore, $2.61 \%$ of the total cohort of patients with involuntary movements and neuropsychiatric features had HDL2 instead.

Among HDL syndromes, HDL2 has the greatest phenotypic similarity to HD. In many cases, clinical manifestations could be almost indistinguishable between the two conditions; ${ }^{19}$ neuropathological

Table 2 JPH3 allelic distribution and frequencies in Venezuelan control individuals ( $n=54$ chromosomes)

\begin{tabular}{lc}
\hline Allele size (no. of repeats) & Frequency \\
\hline 13 & 0.056 \\
14 & 0.685 \\
15 & 0.037 \\
16 & 0.148 \\
17 & 0.037 \\
18 & 0.0185 \\
22 & 0.0185 \\
\hline
\end{tabular}

features are also very similar but HDL2 has a trend generally toward symptoms appearing at a later age of onset. ${ }^{20}$

The four Venezuelan HDL2 index cases had an age of onset between the fourth and fifth decades of life, and three of them had psychiatric manifestation before the onset of involuntary movements (Table 1). Psychiatric disturbances have been reported to be typical in all HDL2 patients, ${ }^{19}$ as was observed in all our patients.

Expanded allele size in Venezuelan cases varied between 39 and 47, the number showing an inverse correlation with age of onset, as expected. The lower size for the pathological expanded alleles as yet has not been well established. An allele with 40 CTG repeats has been reported as low penetrant; ${ }^{9}$ nevertheless, herein we report an expanded allele of 39 uninterrupted CAG/CTG stretch producing late clinical manifestations only at 55 years of age (index case of

Table 4 JPH3 polymorphisms population frequencies

\begin{tabular}{|c|c|c|c|c|}
\hline \multirow[b]{3}{*}{ Polymorphisms } & \multicolumn{4}{|c|}{ Population } \\
\hline & & Sub-Saharan & & \\
\hline & European & African & Asian & Venezuelan \\
\hline \multicolumn{5}{|l|}{ Exon 2} \\
\hline rs918368 & C: 0.54 & C: 0.71 & C: 0.74 & C: 0.63 \\
\hline $917 \mathrm{C}>\mathrm{T}$ & T: 0.46 & T: 0.29 & T: 0.26 & T: 0.37 \\
\hline rs3751725 & $A: 0.25$ & $A: 0.04$ & $A: 0.46$ & A: 0.33 \\
\hline $938 \mathrm{G}>\mathrm{A}$ & G: 0.75 & G: 0.96 & G: 0.54 & G: 0.67 \\
\hline rs34442559 & $\mathrm{C}:-$ & C: - & $\mathrm{C}:-$ & C: 1.00 \\
\hline $992 C>T$ & $\mathrm{~T}:-$ & $\mathrm{T}:-$ & $\mathrm{T}:-$ & T: 0.00 \\
\hline rs9934222 & A: 0.20 & A: 0.17 & A: 0.00 & A: 0.13 \\
\hline $1022 \mathrm{G}>\mathrm{A}$ & G: 0.80 & G: 0.83 & G: 1.00 & G: 0.87 \\
\hline \multicolumn{5}{|l|}{ Intron 3} \\
\hline rs1366520 & C: 0.40 & C: 0.19 & C: 0.53 & C: 0.30 \\
\hline $86819 G>C$ & G: 0.60 & G: 0.81 & G: 0.47 & G: 0.70 \\
\hline Intron 4 & C: 0.30 & C: 0.64 & C: 0.38 & C: 0.60 \\
\hline rs8053904 & G: 0.70 & G: 0.36 & G: 0.62 & G: 0.40 \\
\hline $98543 G>C$ & & & & \\
\hline
\end{tabular}

Table 3 Ancestral origins, ethnic markers and JPH3 haplotypes in phase with mutations in HDL2 index cases

\begin{tabular}{|c|c|c|c|c|c|c|}
\hline Family & Geographic origin (city, state) & $\begin{array}{c}\text { DUFFY null allele } \\
\quad-33 T>C\end{array}$ & $\begin{array}{c}\text { DIEGO DI* } \\
A 2561 C>T\end{array}$ & $\begin{array}{c}K E L L K E L * K \\
698 C>T\end{array}$ & $\begin{array}{l}\text { D9S1120 } \\
\text { alleles }\end{array}$ & $\begin{array}{c}\text { Haplotype of JPH3 } \\
\text { polymorphisms }\end{array}$ \\
\hline 1 & Boca del Tocuyo, Falcón & $\mathrm{T} / \mathrm{C}$ & $\mathrm{C} / \mathrm{C}$ & $\mathrm{C} / \mathrm{C}$ & $17 / 18$ & C;G;C;G;G;- \\
\hline 2 & Guanare, Portuguesa & $T / T$ & $\mathrm{C} / \mathrm{C}$ & $\mathrm{C} / \mathrm{C}$ & $17 / 17$ & $\mathrm{C} ; \mathrm{G} ; \mathrm{C} ; \mathrm{G} ; \mathrm{G} ; \mathrm{C}$ \\
\hline 3 & Río Caribe, Sucre & $\mathrm{T} / \mathrm{C}$ & $\mathrm{C} / \mathrm{C}$ & $\mathrm{C} / \mathrm{C}$ & $18 / 18$ & C;G;C;G;G;- \\
\hline 4 & Cumarebo, Falcón & $\mathrm{T} / \mathrm{C}$ & $\mathrm{C} / \mathrm{C}$ & $\mathrm{C} / \mathrm{C}$ & $9 / 16$ & $\mathrm{C} ; \mathrm{G} ; \mathrm{C} ; \mathrm{G} ; \mathrm{G} ; \mathrm{C}$ \\
\hline
\end{tabular}

Abbreviation: $\mathrm{HDL}$, Huntington disease-like

JPH3-haplotype SNP order (left to right): rs918368 (917C>T, exon 2); rs3751725 (938G>A, exon 2); rs34442559 (992C>T, exon 2); rs993422 (1022G>A, exon 2); rs1366520 (86819G $>$ C, intron 3); and rs8053904 (98543G $>$ C, intron 4).

$(-)$ : family members not informative. 
family 1). Unfortunately, patient descendants were unavailable for study, and thus, allele instability could not be assessed. Another female patient carrying 41 expanded alleles (index case of family 4) transmitted it to two of her offspring, with one repeat expansion in each case (to $42 \mathrm{CTG}$ ); both individuals were still asymptomatic at age 32 and 40 years, respectively.

The estimated HDL2 frequency in Venezuelan patients with involuntary movements is higher than the one reported for Caucasoid populations (between 0 and $1.3 \%)^{2,9,21}$ but much lower than that found in South African patients, which varies between 35 and $45 \% .^{22,23}$ To date, all the worldwide ascertained families have had African origins. ${ }^{9,16,22}$ The reported HDL2 Brazilian patient having an apparent European ancestry carried an African haplotype in phase with the expanded allele, discarding thus a Caucasoid origin for the mutation. ${ }^{24}$ Common African ethnic origin in worldwide patients suggests a very remote ancestral founder effect for the mutation in most human subsets.

In Venezuela, all HD families have a remote Caucasoid origin. ${ }^{10}$ The four unrelated HDL2 Venezuelan families did not have a recent African origin, but remote ancestors in three of them came from geographical areas in which West African slaves were introduced during the colonial period (XVI-XVII centuries); moreover, specific African marker Duffy null allele was carried by these three families, indicating an African background in them. Intragenic SNP alleles in phase with the HDL2 mutation in the four families were those frequent in Sub-Saharan populations, supporting a remote African origin for the mutation in all of them, including the family in which the geographic origin, ancestors' record and the specific ethnic marker Duffy did not suggest a clear African origin. Haplotype sharing in the families might suggest a common and very remote African origin of the mutation, probably not associated with any founder effect in the country.

The prevalence of HDL2 in Venezuela appears to be very low, around $1 / 2000000$ (in the $>40$-year-old population subset of $n=8$ 700000 ), despite the fact that African genes participate as one of the groups giving rise to the current Venezuelan 'general' population, ${ }^{25}$ although at a mean level not higher than $\sim 11 \%$ but with clear geographic stratification. HDL2 therefore should be searched as a first option in those Venezuelan patients with an autosomal dominant pattern of involuntary movements and early psychiatric manifestations, not having a mutation at the HTT locus, as its frequency in the country is clearly higher $(2.6 \%)$ than in other various populations $(0.7 \%),{ }^{21}$ and very high $(25 \%)$ among HDL patients.

\section{CONFLICT OF INTEREST}

The authors declare no conflict of interest.

\section{ACKNOWLEDGEMENTS}

To all the families who generously gave their consent, and to the various physicians who referred us their patients, in particular to Dr Roberto Weiser from Caracas and to the Venezuelan Association for Huntington Disease (AVEHUN).
1 Moore, R. C., Xiang, F., Monaghan, J., Han, D., Zhang, Z., Edström, L. et al. Huntington disease phenocopy is a familial prion disease. Am. J. Hum. Genet. $69,1385-1388$ (2001).

2 Holmes, S. E., O'Hearn, E., Rosenblatt, A., Callahan, C., Hwang, H. S., IngersollAshworth, R. G. et al. A repeat expansion in the gene encoding junctophilin-3 is associated with Huntington disease-like 2. Nat. Genet. 29, 377-378 (2001).

3 Kambouris, M., Bohega, S., Al-Tahan, A. \& Meyer, B. F. Localization of the gene for a novel autosomal recessive neurodegenerative Huntington-like disorder to $4 \mathrm{p} 15.3$. Am. J. Hum. Genet. 66, 445-452 (2000).

4 Rolfs, A., Koeppen, A., Bauer, I., Bauer, P., Buhlmann, S., Topka, H. et al. Clinical features and neuropathology of autosomal dominant spinocerebellar ataxia (SCA17). Ann. Neurol. 54, 367-375 (2003).

5 Schneider, A., Walker, R. \& Bhatia, K. The Huntington's disease-like syndromes: what to consider in patients with a negative Huntington's disease gene test. Nat. Clin. Pract. Neurol. 3, 517-525 (2007)

6 Toyoshima, Y., Yamada, M., Onodera, O., Shimohata, M., Inenaga, C., Fujita, N. et al. SCA17 homozygote showing Huntington's disease-like phenotype. Ann. Neurol. 55, 281-286 (2004).

7 Rasmussen, A., De Biase, I., Fragoso-Benítez, M., Macias-Flores, M. A., Yescas, P. Ochoa, A. et al. Anticipation and intergenerational repeat instability in spinocerebellar ataxia type 17. Ann. Neurol. 61, 607-610 (2007).

8 Bauer, I., Gencik, R. L., Laccone, F., Peters, H., Weber, B. H., Feder, E. H. et al. Trinucleotide repeat expansions in the junctophilin-3 gene are not found in Caucasian patients with a Huntington's disease-like phenotype. Ann. Neurol. 51, 662 (2002).

9 Margolis, R. L., Holmes, S. E., Rosenblatt, A., Gourley, L., O'Hearn, E., Ross, C. A et al. Huntington's disease-like 2 (HDL2) in North America and Japan. Ann. Neurol. 56, 670-674 (2004).

10 Paradisi, I., Hernández, A. \& Arias, S. Huntington disease mutation in Venezuela: age of onset, haplotype analyses and geographic aggregation. J. Hum. Genet. 53, 127-135 (2008).

11 Nakamura, K., Jeong, S. Y., Uchihara, T., Anno, M., Nagashima, K., Nagashima, T. et al. SCA17, a novel autosomal dominant cerebellar ataxia caused by an expanded polyglutamine in TATA-binding protein. Hum. Mol. Genet. 10, 1441-1448 (2001).

12 Imbert, G., Saudou, F., Yvert, G., Devys, D., Trottier, Y., Garnier, J. M. et al. Cloning of the gene for spinocerebellar ataxia 2 reveals a locus with high sensitivity to expanded CAG/glutamine repeats. Nat. Genet. 14, 285-291 (1996).

13 Kawaguchi, Y., Okamoto, T., Taniwaki, M., Aizawa, M., Inoue, M., Katayama, S. et al. CAG expansions in a novel gene for Machado-Joseph disease at chromosome 14q32.1. Nat. Genet. 8, 221-227 (1994).

14 Nagafuchi, S., Yanagisawa, H., Sato, K., Shirayama, T., Ohsaki, E., Bundo, M. et al. Dentatorubral and pallidoluysian atrophy expansion of an unstable CAG trinucleotide on chromosome 12p. Nat. Genet. 6, 14-18 (1994).

15 Schroeder, K. B., Schurr, T. G., Long, J. C., Rosenberg, N. A., Crawford, M. H., Tarskaia, L. P. et al. A private allele ubiquitous in the Americas. Biol. Lett. 3, 218-223 (2007).

16 Bardien, S., Abrahams, F., Soodyall, H., Merwe, L., Greenberg, J., Brink, T. et al A South African mixed ancestry family with Huntington disease like-2: clinical and genetic features. Mov. Disord. 22, 2083-2089 (2007).

17 Martí, M. Documentos relativos a su visita pastoral de la Diócesis de Caracas, 1771-1784, I Libro personal. Bol. Acad. Nac. Hist. 95, 1-637 (1969).

18 Gómez-Canedo, L. Introducción general. In:Martí M. Documentos relativos a su visita pastoral de la Diócesis de Caracas 1771-1784, I Libro Personal Bol. Acad. Nac. Hist. 95, IX-CXI, Caracas (1969).

19 Margolis, R. Huntington disease-like 2. 2009. Available at: http://www.ncbi.nlm nih.gov/sites/GeneTests/review (Accessed 18 January 2012).

20 Rudnicki, D. D., Pletnikova, O., Vonsattel, J. P., Ross, C. A. \& Margolis, R. L. A comparison of Huntington disease-like 2 neuropathology. J. Neuropathol. Exp. Neurol. 67, 366-374 (2008).

21 Wild, E. J., Mudanohwo, E. E., Sweeney, M. G., Schneider, S. A., Beck, J., Bhatia, K. P. et al. Huntington's disease phenocopies are clinically and genetically heterogeneous. Mov. Disord. 23, 716-720 (2008).

22 Magazi, D. S., Krause, A., Bonev, V., Moagi, M., Iqbal, Z. \& van der Meyden, C. H. Huntington's disease: genetic heterogeneity in black African patients. S. Afr. Med. J. 98, 200-203 (2008).

23 Margolis, R. L., Rudnicki, D. D. \& Holmes, S. Huntington's disease like-2: review and update. Acta Neurol. Taiw. 14, 1-8 (2005).

24 Santos, C., Wanderley, H., Vedolin, L., Pena, S. D., Jardim, L. \& Sequeiros, J. Huntington disease-like 2: the first patient with apparent European ancestry. Clin. Genet. 73, 480-485 (2008).

25 Castro de Guerra, D., Figuera Pérez, C., Izaguirre, M. H., Arroyo Batahona, E. Rodríguez Larralde, A. \& Vívenes de Lugo, M. Gender differences in ancestral contribution and admixture in Venezuelan populations. Hum. Biol. 83, 345-361 (2011) 